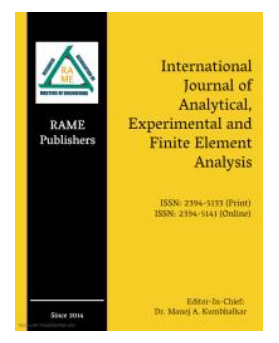

Mahesh Buradkar maheshburadkar@rediffmail.com

Shubham Masamwar ${ }^{2}$ shubhammasamwar@gmail.com

Sahil Kolhe ${ }^{2}$ kolhesahil358@gmail.com

Kunal Daiwalkar daiwalkarkunal@gmail.com

Khushal Mandhare ${ }^{2}$ khushalmandhare.9@gmail.com

Sandip Thengane ${ }^{2}$ sandipthengane2015@gmail.com

Runal Patil ${ }^{2}$ runalpatil0@gmail.com

${ }^{1}$ Assistant Professor and ${ }^{2}$ Student, Department of Mechanical Engineering, Rajiv Gandhi College of Engineering, Research and Technology, Chandrapur, India

\section{INTRODUCTION}

At each end of the tool posts, a dual slide shaper machine has two working strokes. The major benefit of a dual sider shaper machine is that it reduces manufacturing time and costs, thereby improving productivity. Though, in our project, we turned the ideal stroke, which was supposed to be idle, into a working stroke by adding a tool post and a tool at the opposite end. The idea of the scotch yoke rapid return mechanism was then used. The cost can be lowered at first, and the rate of production can be increased, making it a suitable dual sider shaper machine.

Research Paper - Peer Reviewed

Published online - 1 September 2021

(C) 2021 RAME Publishers

This is an open access article under the CC BY 4.0 International License https://creativecommons.org/licenses/by/4.0/

Cite this article - Mahesh Buradkar, Shubham Masamwar, Sahil Kolhe, Kunal Daiwalkar, Khushal Mandhare, Sandip Thengane, Runal Patil, "Design of Dual Slider Shaper Machine", International Journal of Analytical, Experimental and Finite Element Analysis, RAME Publishers, vol. 8 , issue 3 , pp. 108-112, 2021.

https://doi.org/10.26706/ijaefea.3.8.20210712

\title{
Design of Dual Slider Shaper Machine
}

\begin{abstract}
The tools are usually shaped using a shaping machine, which can be horizontal, vertical, or tending. Materials are moulded from both ends in a dual sider shaper machine, making it more advantageous than a regular shaper. Dual Sider Shaper of a rapid return mechanism. The motor's rotating action is transformed into linear motion, which shapes the material attached to both ends. The rapid return mechanism converts reciprocating momentum into rotating motion.
\end{abstract}

Keywords-Shaper, rapid return mechanism, turning motion, materials, linear motion, flywheel.

\section{A. Aim \& Objectives}

The major goal and objective of the project was to develop a multi-use dual sider shaper machine with as little time wastage as possible, because the return stroke was conducted while the machine was idle. However, by attaching a tool-post and a workpiece to their respective ends, we were able to convert that idle return stroke into a productive stroke.

\section{B. Problem Statement}

Nowadays, industries strive for a high output rate with the least amount of time, money, and effort. A shaper is a machine that is used to shape (remove metal from) a work piece and to machine a single job with a single point cutting tool, therefore it cannot be utilised for large production rates. The work will be machined during the forward stroke of the tool, and the tool will be idle during the reverse stroke. Both sides of shaper machine shaping operations are possible in order to utilise idling time and enhance productivity while lowering cost and production time. Another advantage is that there are fewer moving parts than in a traditional machine. We may make minor 
adjustments to our project "Design of Dual Slider Shaper Machine" and attach another tool post to conduct the dual operation (both forward and back stroke) in the shaper machine. As a result, manufacturing time, labour, and expenses will be reduced, resulting in increased efficiency and production rate.

\section{RELATED WORK}

The following literature papers are referred for the design and analysis of dual slider shaper machine and cited.

The shaper machine is used to remove metal chips from a high-speed steel blank in order to achieve a defined structure. The metal in the blank will be removed solely in the forward stroke of a conventional shaper machine, while the chips will not be removed in the backward stroke. The chips will be removed from the dual side shaper machine during both forward and backward strokes. Individual machines are used in industries to perform shaping and grinding processes [1].

To illustrate the dual side machining time reduction in shaping machines, a tiny Scotch yoke mechanism was built. During the return motion of this shaping machine, there is an idle stroke. The idle stroke is used as a cutting stroke in this project, which enhances the output rate. This may be accomplished by including a clapper box with a tool, such that the arrangement on tool and the arrangement on tool holder both have one tool fastened on the clapper box. To get the forward and return strokes, the motor source of power with switch accessories is utilized to operate the ram on the guide plate. The machining time of a work item is cut in half thanks to this arrangement. This device allows for shaping operations on both sides of the shaper machine [2].

Materials are treated on both ends in a dual side shaper machine, making it more beneficial than a traditional shaper. Nowadays, industries strive for a high output rate with the least amount of time, money, and effort. The use of a dual side shaper machine removes the majority of the drawbacks associated with a single side shaper. The major benefit of a dual side shaper is that it reduces both time and manufacturing costs. This type makes use of a single power source that may be linked to gears to change the cutting speed [3].

A shaper is a machine that is used to shape (remove metal from) a work item. A typical shaper machine works on the idea of a whit worth fast return mechanism, in which materials are treated at one end while the other is idle. However, with a dual side shaper machine, materials are treated on both ends, making it more beneficial than a standard shaper. This project was designed with preplanning in mind, allowing for operational flexibility. This invention has made the more appealing and cost-effective. This project was created with the hopes of being highly cost effective, and it also taught us the procedures involved in finishing a project. As a result, the project was successfully finished [4].

\section{WORKING PRINCIPAL}

The machine must be installed on metal that is soldered together to ensure rigidity. Only the connecting rod is permitted to move in a straight line. When the motor receives an $\mathrm{AC} / \mathrm{DC}$ current from the power supply. The flywheel is attached to the motor. Similarly, the belt drive system provides a rotational drive for the flywheel. The flywheel and the disc are both placed on the same shaft. A pin is attached to the disc and is hinged at the slotter. When the disc rotates, the crank that is aligned with the slotter rotates in a linear motion. The tool post is attached at the end of the crank, and the single point cutting tool is used to remove the material from the workpiece. During the machining process, the workpiece is held in place by a clamp.

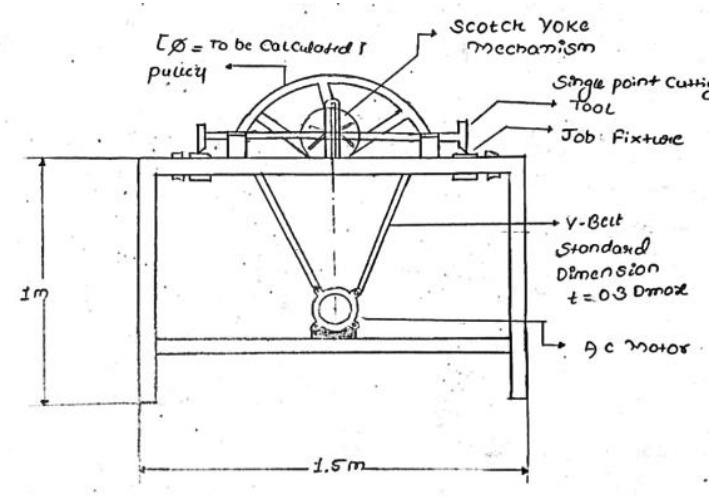

Figure 1: Sketch of dual side shaper machine 


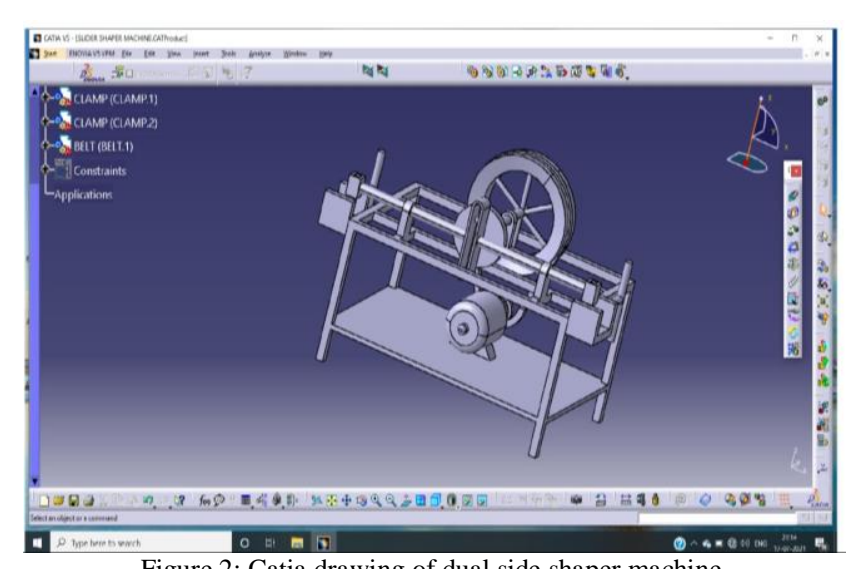

Figure 2: Catia drawing of dual side shaper machine

\section{COMPONENTS DETAILED}

\section{A. Scotch Yoke Mechanism}

A Scotch Yoke (also known as a slotted link mechanism) is a reciprocating motion mechanism that converts a slider's linear motion into rotating motion or vice versa. A sliding yoke with a slot that contacts a pin on the rotating portion is directly linked to the piston or other reciprocating part. When the shaft begins to spin, the crankpin now turns the slider within the yoke portion and advances in the forward direction. When the yoke is in a forward-facing displacement moment and the crank is turned counter clockwise The yoke's maximum displacement is determined by the crank's length.

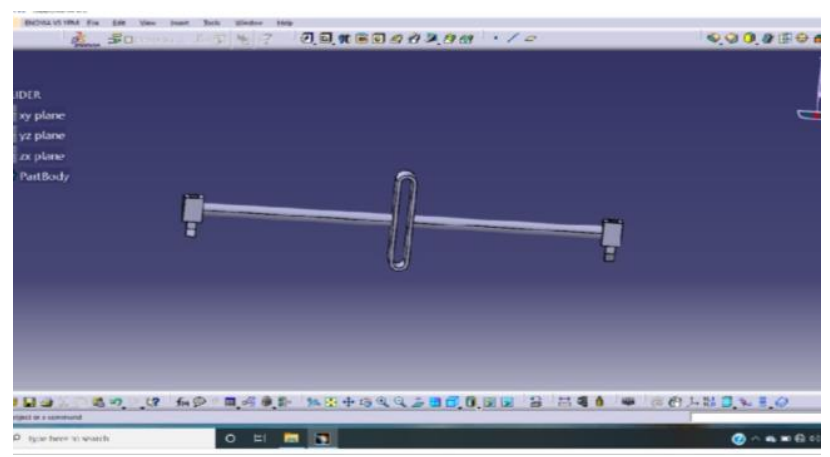

Figure 3: Scotch Yoke Mechanism

\section{B. Flywheel}

A flywheel is a mechanical device that is designed to store rotational energy, which is proportional to the product of its moment of inertia and the square of its rotating speed, using the conservation of angular momentum. The flywheel's inertia resists and moderates' variations in the engine's speed, and it stores the extra energy for intermittent use. A flywheel is given a high rotational inertia to effectively counter speed variations; that is, most of its weight is widely out from the axis. The rotational inertia of a wheel with a hefty rim linked to the central hub by spokes or a web is considerable. The energy stored in a flywheel, on the other hand, is dependent on both the weight and the diameter of the wheel, and it will burst at a considerably lower rotational speed than a disk-type wheel of the same weight and diameter. For minimal distribution and rotational speed, doubling the speed quadruples the kinetic energy. A flywheel may be composed of highstrength steel and fashioned as a tapered disc, thick in the middle and thin at the rim, with a rim-type flywheel weight and high energy-storing capacity.

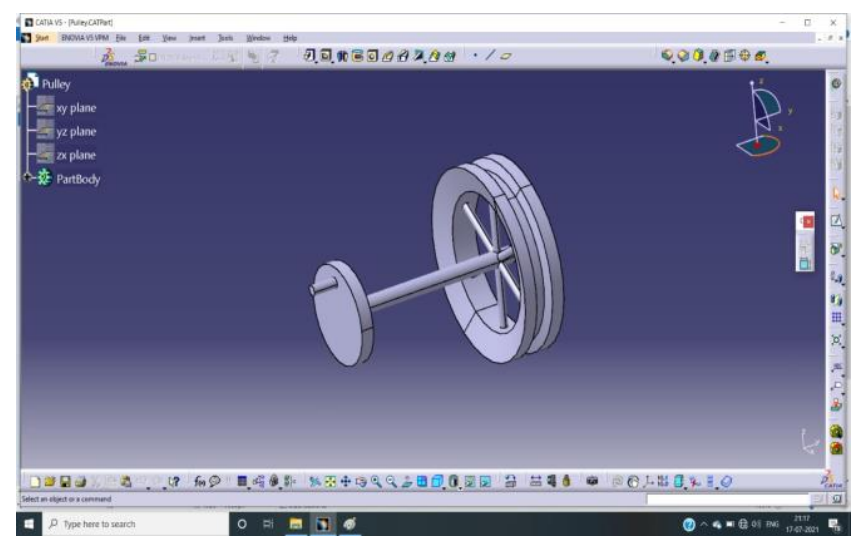

Figure 4: Flywheel

\section{Electric Motor}

An electrical motor is a device that transforms electrical energy into mechanical energy. The electro-mechanical mechanism that transforms electrical energy into mechanical energy is known as an electric motor. The motor, in other terms, is a device that produces rotating force. The interplay of magnetic and electric fields is fundamental to the operation of an electric motor. Electric motors are divided into two categories. The AC motor and the DC motor are the two types of motors. The AC motor is powered by alternating current, whereas the DC motor is powered by direct current. Electric motors provide torque (linear or rotational force) that is used to move an external mechanism such as a fan or an elevator. Electric motors are often built for continuous rotation or linear movement over a large distance given their size. Magnetic solenoids are 
likewise transducers that transfer electrical power to mechanical motion, but they have a restricted range of motion.

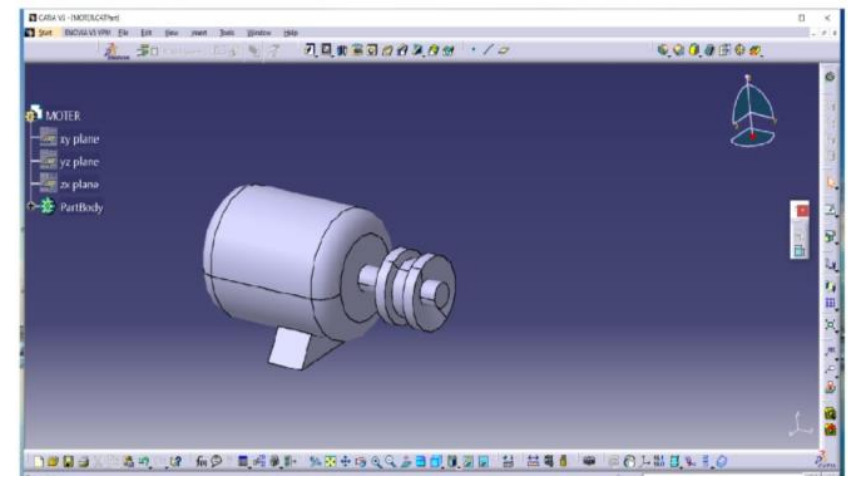

Figure 5: Electrical Motor

\section{Belt Drive}

Because of the frictional grip between the belt and the pulley surface, mechanical power or rotary motion is delivered from the driving pulley to the driven pulley. Slack side refers to the section of the belt with the least tension, whereas tight side refers to the area with the most stress. The difference in tension between the slack and tight sides determines the belt's effective pulling force, which causes the driven pulley to rotate.

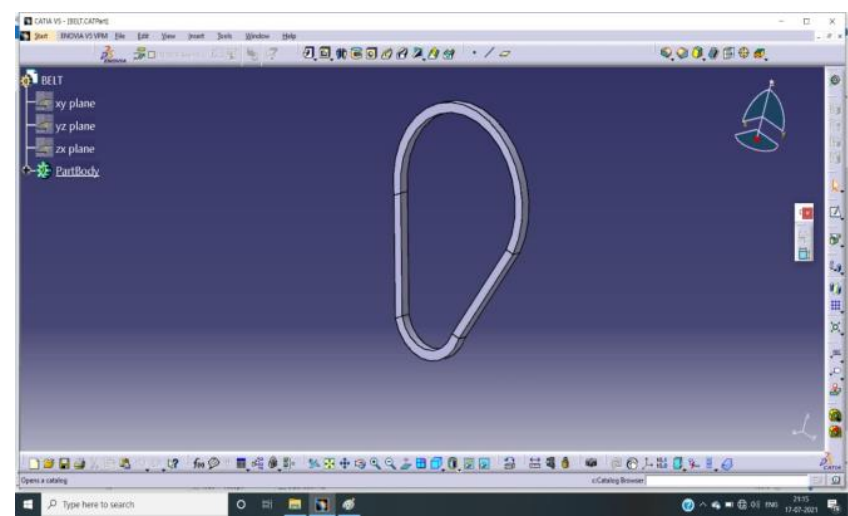

Figure 6: Belt Drives

\section{E. Machine Tool}

To manufacture a linear tool path, a machine tool employs the linear relative motion between the work piece and a single-point cutting tool. The ram is usually controlled by a mechanical crank inside the column, although hydraulically controlled shapers are becoming more popular.

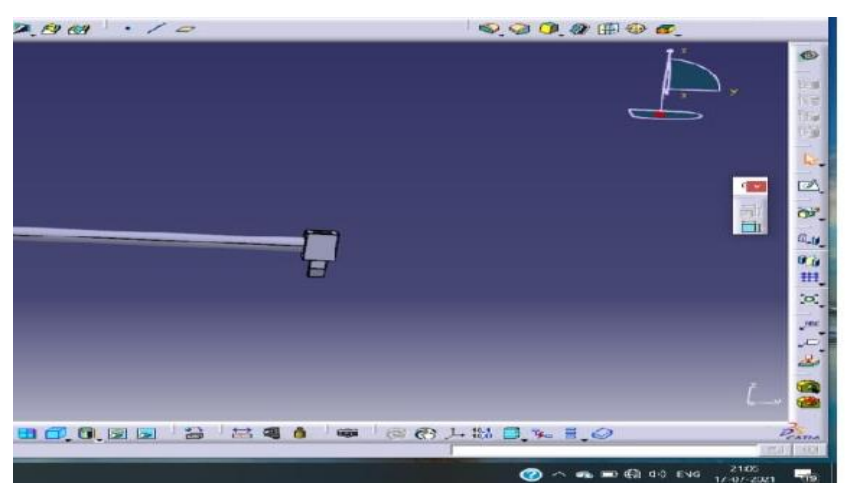

Figure 7: Machine Tool

\section{DESIGN FOR INPUT AND OUTPUT PARAMETER}

Based on the input parameter identified, the output parameter for the design of dual slider shaper machine have been calculated and the comparison with traditional machine is given in table 1 .

\section{Design specifications}

Diameter of crank $=0.30 \mathrm{~m}$

Length of slotted bar $=0.202 \mathrm{~m}$

Length of connecting rod $=0.51 \mathrm{~m}$

\section{Cutting Force}

Power $=630$ watts

Speed $=210 \mathrm{rpm}$

$\mathrm{P}=2 \pi \mathrm{NT} / 60$

$\mathrm{T}=28.64 \mathrm{Nm}$

We know that,

Torque $=$ Force $\times$ Radius of crank

$\mathrm{F}=190 \mathrm{~N}$

\section{Design of shaft}

Diameter of the shaft $=0.03 \mathrm{~m}$

Permissible shear stress for mild steel $=34 \mathrm{~N} / \mathrm{m}^{2}$

$\mathrm{T}_{1}=\pi / 16 \times\left(\mathrm{f}_{\mathrm{s}}\right) \mathrm{x} \mathrm{d}^{3}$

$\mathrm{f}_{\mathrm{s}}=6573688.612 \mathrm{~N} / \mathrm{m}^{2}$

$F_{\mathrm{s}}=6.573 \mathrm{~N} / \mathrm{mm}^{2}<$ fs permissible $=34 \mathrm{~N} / \mathrm{mm}^{2}$

Therefore, the design is safe

\section{Cutting speed}

Cutting speed $\mathrm{v}=\mathrm{NL}(1+\mathrm{m}) / 1000 \mathrm{~m} / \mathrm{min}$ 
$\mathrm{N}=$ the number of double strokes or cycle of the ram per $\min ($ take $\mathrm{N}=100)$

$\mathrm{L}=$ length of the ram stroke in $\mathrm{mm}$

$\mathrm{m}=$ return stroke time/cutting stroke time, $\mathrm{m}=1$

$\mathrm{v}=0.021 \mathrm{~m} / \mathrm{min}$

TABLE I

COMPARISON FOR THE OUTPUT PARAMETER OF TRADITIONAL AND DUAL SLIDER SHAPER MACHINE

\begin{tabular}{|l|l|l|l|l|}
\hline Machine & Cost & Time & Productivity & $\begin{array}{l}\text { Moving } \\
\text { part }\end{array}$ \\
\hline $\begin{array}{l}\text { Traditional } \\
\text { Shaper } \\
\text { machine }\end{array}$ & Increase & Increase & Decrease & More \\
\hline $\begin{array}{l}\text { Dual side } \\
\text { shaper } \\
\text { machine }\end{array}$ & Decrease & Decrease & Increase & Less \\
\hline
\end{tabular}

\section{Conclusion And Future Scope}

The dual side shaper machine appears to be the result of combining two existing shaper machines. The major benefit of utilising a dual side shaper machine is that it reduces both manufacturing time and cost. As a result, productivity rises. Another advantage is that there are fewer moving parts than in a traditional machine. The innovative aspect of our project is that the ideal stroke, which was originally intended to be left idle, is now employed as the working stroke. Increasing its efficiency while giving it a strong implementation purpose (percent). A dual slider shaper machine may be used in a variety of businesses that use multi-purpose machines. These machines will assist in cost reduction, increased production rate, and increased expertise.

With respect to the work carried out, the scope for future work is given below.

1. This project can be fabricated by using different materials.

2. It can be made portable and easily install as per the requirement and working condition.

3. Grinding wheel can be attached and perform multiple operation at the same time.

\section{REFERENCES}

[1] Mr. R. Ragavendiran, M. Akash, D. Aravind, S. Dinesh Kumar, "Dual side shaper machine and grinding wheel attachment using scotch yoke mechanism", International Journal of Research Culture Society, Volume - 2, Issue -1, Feb- 2018.

[2] Veldi Kanakaraju, Manga Hymanjali, Boda Ramesh, Kanjarla Shyam Kumar, "Fabrication of Dual Side Shaper Machine using Scotch Yoke Mechanism”, International Journal of Engineering Research \& Technology (IJERT), Vol. 8 Issue 07, July-2019.

[3] Kamalnath.V, Kameshwaran.S, "Design and Analysis of Dual Side Shaper Using Scotch Yoke Mechanism", International Journal of Innovative Research in Science, Engineering and Technology, Vol. 6, Issue 7, July 2017.

[4] D. Anbazhagan, M. Kanagaraj, S. Kannan, M. Sivakumar, G. Vijaykumar, "Design And Fabrication Of Dual Side Shaper Machine Using Scotch Yoke Mechanism”, International Journal of Advance Research and Innovative Ideas in Education, Vol-4 Issue-2 2018.

[5] R. S. Khurmi, J. K. Gupta, "A textbook of Manufacturing Process", S. Chand Publication., 2010.

[6] R. K. Jain, "Manufacturing Processes, Technology and Automation", Khanna Publishers, Volume II, $18^{\text {th }}$ edition, 2001.

[7] Different Types of Cutting Tools Materials and Their Properties. Available at-

https://www.mecholic.com/2016/02/different-types-ofcutting-tools-materials-and-their-properties.html

[8] Types of Bearings and Thier Applications, JVV Bearings. Available at-

https://jvnbearings.com/2019/05/25/types-of-bearings-andthier-applications/

[9] Electric Motor, Circuit Globe. Available athttps://circuitglobe.com/electric-motor.html

[10] Rajkumar Gupta, Principle, working and construction of Scotch Yoke Mechanism. Available athttps://mechanicaljungle.com/construction-of-scotch-yoke$\underline{\text { mechanism/ }}$ 